\title{
A STUDY OF COMPLICATIONS IN SUBJECTS WITH SNAKE BITE IN RELATION TO TIMING OF ASV ADMINISTRATION IN A TERTIARY CARE HOSPITAL
}

\author{
Ramesh S. S. ${ }^{1}$ Shivakumar H. R2
}

${ }^{1}$ Associate Professor, Department of Medicine, Mysore Medical College and Research Institute.

2Postgraduate Student, Department of Medicine, Mysore Medical College and Research Institute.

\begin{tabular}{l}
\hline ABSTRACT \\
BACKGROUND \\
India is a tropical country, where snake bite is a major public health problem. It is a common occupational hazard mainly in \\
farmers and rural population are affected mainly. India is reported to have highest number of snake bites. Apart from the mortality, \\
the morbidity caused by snake bite is also high in India. Administration of ASV as early as possible can prevent many of the \\
complications and even death if given in time. \\
The aim of this study is to study the various complications of snake bite in relation to the timing of ASV administration.
\end{tabular}

\section{MATERIALS AND METHODS}

The study was carried out over a period of 8 months by including 50 cases of snake bite. A detailed clinical history regarding bite time since bite, symptoms of envenomation and complications were taken at the time of presentation. Thorough clinical examination was then carried out and also relevant laboratory investigations were sought.

\section{RESULTS}

Among these 50 patients, $66 \%$ were males and 34\% were females. Male preponderance may be attributed to their lifestyles involving outdoor activities and occupational exposures. Majority of the patients were $<30$ years of age, $34 \%$. Among the 50 patients 30 had complications, out of these $50 \%$ of them had haematological complication, $4 \%$ had neurological complications, $28 \%$ had renal complication, $4 \%$ had cardiovascular complications and $26 \%$ had local complications. Those who presented within 6 hours complications were $50 \%$ and those who presented late i.e. after 24 hours complication rate was high $100 \%$ as we noted in our study.

\section{CONCLUSION}

The complication rate was less in those who presented within 6 hours since bite, whereas complication rate was high in those who presented late, though ASV was administered immediately wherever indicated. This implies the importance of early presentation to hospital and initiation of treatment with ASV will prevent the complications in snake bite.

\section{KEYWORDS}

Envenomation, Snake Bite, ASV, Complications, WBCT, AKI.

HOW TO CITE THIS ARTICLE: Ramesh SS, Shivakumar HR. A study of complications in subjects with snake bite in relation to timing of ASV administration in a tertiary care hospital. J. Evolution Med. Dent. Sci. 2017;6(92):6651-6654, DOI: $10.14260 /$ jemds/2017/1440

\section{BACKGROUND}

Snake bite is a major health problem in tropical countries like India, where rural population are mainly affected. The true global burden of snake bite is not known due to lack of standardised reporting. However, India is reported to have highest number of snake bites and about 15,000 patients are reported dying every year from venomous snake bites in India. ${ }^{1}$ Apart from the mortality, the morbidity caused by snake bite is also high in India. Administration of ASV as early as possible can prevent many of the complications and even death if given in time. However, superstitions, lack of prompt medical access, late reporting to health care systems and cost of ASV delays the administration of ASV.

'Financial or Other Competing Interest': None. Submission 03-10-2017, Peer Review 15-11-2017,

Acceptance 21-11-2017, Published 04-12-2017.

Corresponding Author:

Dr. Shivakumar H.R.

Postgraduate in Medicine, Department of Medicine,

Mysore Medical College and Research Institute,

Irwin Road,

Mysore-570001.

E-mail: shivgowdahosur@gmail.com

DOI: $10.14260 /$ jemds $/ 2017 / 1440$

\section{(c) $($ ) $\odot$}

Therefore, we are taking this priority area to study the various complications of snake bite in relation to the timing of ASV administration.

\section{MATERIALS AND METHODS}

The present study is an observational study and it was carried out over a period of 8 months in our hospital, which is a tertiary care centre and a teaching hospital in the state. All those patients who are $>18$ years age and presenting to the casualty department with snake bite were included in the present study and prospectively studied. Snake bite and species identification was confirmed by a reliable history from the patient, those who witnessed the bite and patient's bystanders. All patients were interviewed using a standard questionnaire to maintain a record of patient's history relevant to snake bite envenomation.

In this study, all cases of snake bite $\geq 18$ years age who gave informed written consent were included. Those who are $<18$ years of age, pregnant patients and those with preexisting comorbidities like diabetes mellitus, hypertension and ischaemic heart disease are excluded. By going through the above-mentioned inclusion and exclusion criteria, 50 patients were included for the study. 
A detailed clinical history regarding bite, time since bite, symptoms of envenomation and complications were taken at the time of presentation. Thorough clinical examination was then carried out. Relevant laboratory investigations like complete blood count, whole blood clotting time, renal function test, liver function tests, prothrombin time, activated partial thromboplastin time, international normalised ratio, random blood glucose and serum electrolytes were done. The time taken by the patient to arrive at the hospital from the time of bite was noted. The patients were then prospectively studied to note the development of any complications.

Haematological envenomation is said to be present if the patient has whole blood clotting time $>20$ minutes, thrombocytopenia and deranged coagulation profile. Neurological envenomation was said to be present if the patient has ptosis, diplopia, dyspnoea or respiratory muscle weakness. Local complications like cellulitis, gangrene and compartment syndrome were noted. Oliguria and deranged renal function tests were taken as renal complication.

\section{Statistical Methods}

The statistical methods used are descriptive, Chi-square test and cross-tabs (Cramer's V test).

\section{RESULTS}

The study was done on total 50 patients with snake bite who got admitted in our hospital. Among these patients, $66 \%$ $(n=33)$ were males and $34 \%(n=17)$ were females.

\begin{tabular}{|c|c|}
\hline Male & $66 \%$ \\
\hline Female & $34 \%$ \\
\hline \multicolumn{2}{|c|}{ Table 1. Gender Distribution } \\
\hline
\end{tabular}

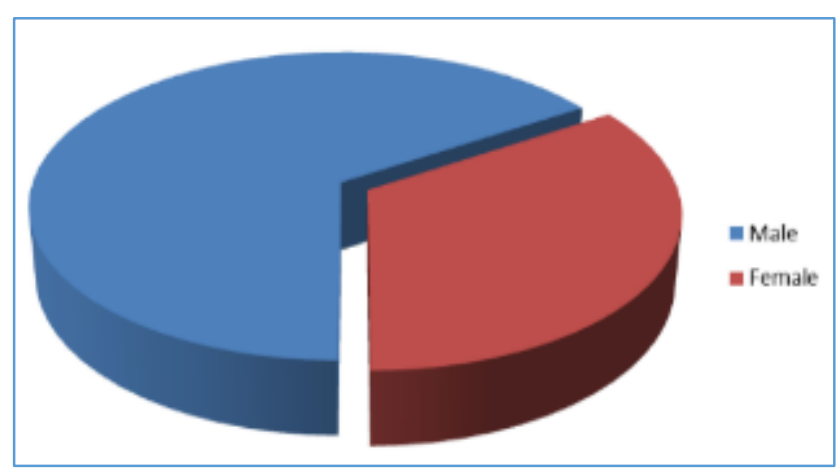

Figure 1. Gender Distribution

Majority of the patients were $<30$ years of age $34 \%(n=17)$ and $8 \%(n=4)$ belonged to age $>60$ years.

\begin{tabular}{|c|c|}
\hline Age in Years & Number \\
\hline$<30$ & 17 \\
\hline $31-40$ & 10 \\
\hline $41-50$ & 10 \\
\hline $51-60$ & 9 \\
\hline$>60$ & 4 \\
\hline \multicolumn{2}{|c|}{ Table 2. Age Distribution } \\
\hline
\end{tabular}

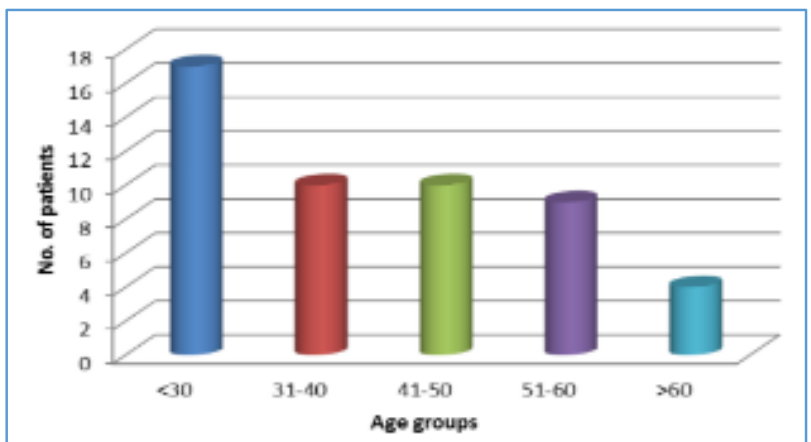

Figure 2. Age Distribution

Among the 50 subjects 30 had complications such that $50 \%$ of them had haematological complications, $4 \%$ had neurological complications, $28 \%$ had renal complications, $4 \%$ had cardiovascular complications and $26 \%$ had local complications.

\begin{tabular}{|c|c|c|c|c|c|}
\hline WBCT & Cobra & Viper & Krait & Unknown & Total \\
\hline$<20 \mathrm{~min}$ & 4 & 1 & 0 & 22 & 27 \\
\hline$>20 \mathrm{~min}$ & 4 & 7 & 1 & 10 & 22 \\
\hline Not done & 0 & 1 & 0 & 0 & 1 \\
\hline Total & $\mathbf{8}$ & $\mathbf{9}$ & $\mathbf{1}$ & $\mathbf{3 2}$ & $\mathbf{5 0}$ \\
\hline Table 3. WBCT at Admission in Relation to Type of Snake \\
\hline
\end{tabular}

(Chi-square test, $\mathrm{p}$ value 0.02 )

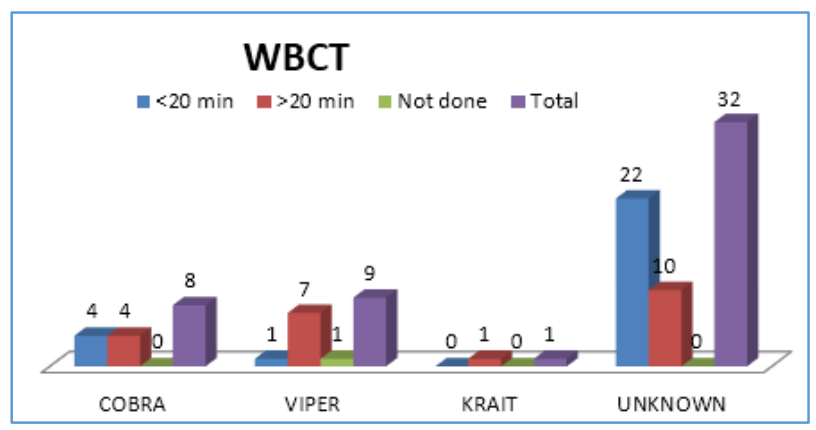

Figure 3. WBCT at Admission in Relation to Type of Snake

Whole blood clotting time is increased in patients with viper bites and unknown bites at presentation, may be because of majority of the unknown bites are poisonous.

Total 14 patients developed AKI, 5 viper bite patients and 9 unknown bite patients developed AKI.

\begin{tabular}{|c|c|c|c|c|c|}
\hline AKI & Cobra & Viper & Krait & Unknown & Total \\
\hline Yes & 0 & 5 & 0 & 9 & 14 \\
\hline No & 8 & 4 & 1 & 23 & 36 \\
\hline \multicolumn{7}{|c|}{ Table 4. AKI in Relation to Type of Snake } \\
\hline
\end{tabular}

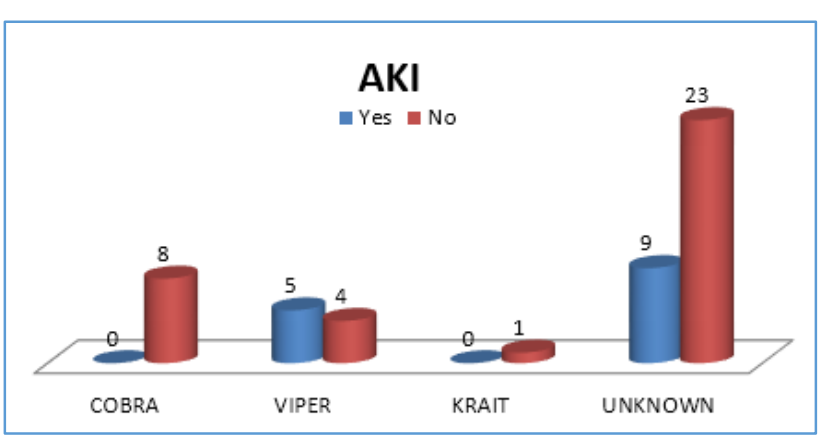

Figure 4. AKI in Relation to Type of Snake 
All patients who attended our hospital received treatment without delay. Those who presented within 6 hours, complications noted were $50 \%$ and those who presented after 24 hours complication rate was high as $100 \%$ as we noted in our study.

\begin{tabular}{|c|c|c|c|c|}
\hline Complication & $\begin{array}{c}<6 \\
\text { hours }\end{array}$ & $\begin{array}{c}\mathbf{7 - 1 2} \\
\text { hours }\end{array}$ & $\begin{array}{c}\mathbf{1 3 - 2 4} \\
\text { hours }\end{array}$ & $\begin{array}{c}>\mathbf{2 4} \\
\text { hours }\end{array}$ \\
\hline No & $50 \%$ & $20 \%$ & $25 \%$ & $0 \%$ \\
\hline Yes & $50 \%$ & $80 \%$ & $75 \%$ & $100 \%$ \\
\hline Table 5. Complication Rate in Relation to the Time since \\
Snake Bite \\
\hline
\end{tabular}

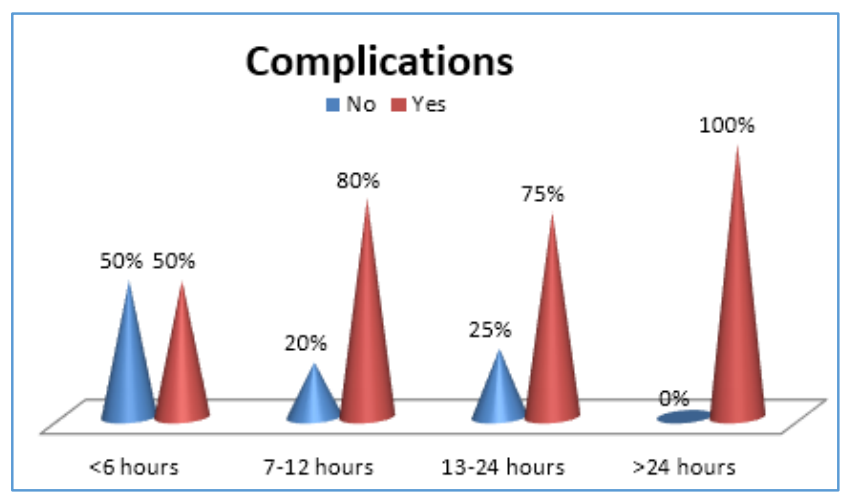

Figure 5. Complication Rate in Relation to the Time since Snake Bite

The number of ASV requirement also depends on type of snake- 3 viper bites, 1 cobra bite and 1 unknown bite required more than 30 vials of ASV in the present study.

\begin{tabular}{|c|c|c|c|c|}
\hline $\begin{array}{c}\text { Duration } \\
\text { since Snake } \\
\text { Bite in } \\
\text { Hours }\end{array}$ & $\begin{array}{c}\text { Number } \\
\text { of Cases } \\
\text { Presented }\end{array}$ & $\begin{array}{c}\text { Number } \\
\text { of Cases, } \\
\text { ASV given }\end{array}$ & $\begin{array}{c}\text { Number } \\
\text { of Cases } \\
\text { Complicated }\end{array}$ & $\begin{array}{c}\text { Percentage } \\
\text { of Cases } \\
\text { Complicated }\end{array}$ \\
\hline $0-6$ & 34 & 19 & 17 & $50 \%$ \\
\hline $7-12$ & 5 & 3 & 4 & $80 \%$ \\
\hline $13-24$ & 8 & 7 & 6 & $75 \%$ \\
\hline$>24$ & 3 & 0 & 3 & $100 \%$ \\
\hline \multicolumn{5}{|c|}{ Chi-square test for trend 'p' value is 0.035 } \\
\hline Table 6. Administration of ASV in Relation to Duration \\
since Snake Bite and Complications \\
\hline
\end{tabular}

The number of subjects presented to hospital is more in 0-6 hours and ASV was administered immediately. Among these subjects, $50 \%$ of them developed complications. Subjects presented later, though the ASV instituted immediately wherever indicated, the complication rate has increased in relation to the duration since snake bite and ASV administration.

\begin{tabular}{|c|c|c|c|c|}
\hline No. of Vials of ASV & Cobra & Viper & Krait & Unknown \\
\hline NIL & 0 & 2 & 0 & 19 \\
\hline $1-9$ & 0 & 0 & 0 & 1 \\
\hline $10-19$ & 4 & 2 & 0 & 9 \\
\hline $20-29$ & 3 & 2 & 1 & 2 \\
\hline$>30$ & 1 & 3 & 0 & 1 \\
\hline Total & $\mathbf{8}$ & $\mathbf{9}$ & $\mathbf{1}$ & $\mathbf{3 2}$ \\
\hline Table 7. ASV Requirement in Relation to Type of Snake \\
\hline
\end{tabular}

(Chi-square test, $\mathrm{p}$ value 0.017 )

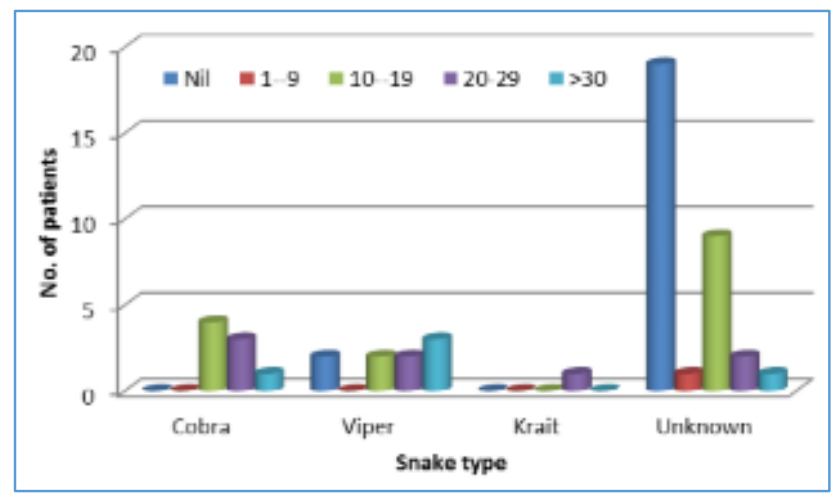

Figure 6. ASV Requirement in Relation to Type of Snake

\section{DISCUSSION}

The present study was carried out on 50 cases of snake bite. Male preponderance seen in our study $(66 \%)$ is in close agreement with earlier studies.2,3,4,5 Sharma et al 4 found $73 \%$ males and $27 \%$ females in their study and also Brunda et al ${ }^{2}$ found male preponderance of $76 \%$. It may be attributed to their lifestyles involving outdoor activities and occupational exposures, ${ }^{3}$ while most of the females in our state are usually housewives, thus less prone for snake bites.

It is evident that maximum number of cases belong to $<30$ years' age group (34\%), while only $8 \%$ belong to $>60$ years. It may be attributed to their lifestyles and occupational exposures. Also, most of the patients in the present study belong to rural areas, which are nearby to Mysore.

\begin{tabular}{|c|c|c|c|c|}
\hline & $\begin{array}{c}\text { Sharma } \\
\text { et al }\end{array}$ & $\begin{array}{c}\text { Brunda } \\
\text { et al }\end{array}$ & $\begin{array}{c}\text { Chattopadhyay } \\
\text { et al5 }\end{array}$ & $\begin{array}{c}\text { Present } \\
\text { Study }\end{array}$ \\
\hline$<30$ years & $76 \%$ & $60 \%$ & $60 \%$ & $34 \%$ \\
\hline$>60$ years & $10 \%$ & $11 \%$ & $15 \%$ & $8 \%$ \\
\hline
\end{tabular}

\section{Table 8. Comparison of Present Study with Other Studies}

Among the 50 patients, 30 cases $(60 \%)$ had variety of complications and the remaining 20 cases did not have any complications. An attempt was made in the present study to find the relationship between the development of complications and timing of ASV administration and other treatment since bite due to late arrival of patient to hospital.

In the present study, 34 cases presented to hospital within 6 hours following bite. Among these 17 cases had complications at the time of presentation, whereas 3 cases presented after 24 hours since bite and all 3 of them had complications. Another 10 cases with complications are presented between 6 - 24 hours since bite. Cramer's V test was employed which showed approximate significance of 0.22 (0.438). Hence, it shows that incidence of complications is directly proportional to the duration of venom in the blood prior to neutralisation by ASV as studied earlier by Vijetha SR et al. ${ }^{6}$ Among the 50 subjects 30 had complications such that $50 \%$ of them had haematological complications, $4 \%$ had neurological complications, $28 \%$ had renal complications, $4 \%$ had cardiovascular complications and $26 \%$ had local complications.

In the present study 14 patients had AKI and among them only 2 cases went for haemodialysis. These 2 patients presented late as well, i.e. after 24 hours from bite time. A study conducted by Ash et $\mathrm{al}^{7}$ and Thomas $\mathrm{L}$ et al ${ }^{8}$ documented a positive correlation between severity of renal 
failure and increase in time interval between the bite and ASV administration.

Among 8 cases of cobra bite only 2 cases had neuroparalysis and respiratory failure and required mechanical ventilator support.

\section{Limitation of the Study}

In the present study, the limitation was less number of study subjects.

\section{CONCLUSION}

In the present study 30 cases had complications such that $50 \%$ of them had haematological complications, $4 \%$ had neurological complications, $28 \%$ had renal complications, $4 \%$ had cardiovascular complications and $26 \%$ had local complications.

All patients received treatment without delay. The complication rate was less in those who presented within 6 hours since bite, whereas complication rate was high in those who presented late, though ASV was administered immediately wherever indicated. This implies that importance of early presentation to hospital and initiation of treatment with ASV will prevent the complications in snake bite.

\section{REFERENCES}

[1] Sahare P, Chaturvedi P. Snake poisoning in children. Indian Practitioner 1997;50:979-85.
[2] Brunda G, Sashidhar RB. Epidemiological profile of snake-bite cases from Andhra Pradesh using immunoanalytical approach. Indian Journal of Medical Research 2007;125(5):661-8.

[3] Saravu K, Somavarapu V, Shastry AB, et al. Clinical profile, species specific severity grading, and outcome determinants of snake envenomation: an Indian tertiary care hospital based prospective study. Indian Journal of Critical Care Medicine 2012;16(4):187-92.

[4] Sharma SK, Khanal B, Pokhrel P, et al. Snake bite reappraisal of the situation in Eastern Nepal. Toxicon 2003;41(3):285-9.

[5] Chattopadhyay S, Sukul B. A profile of fatal snake bite cases in the Bankura district of West Bengal. Journal of Forensic and Legal Medicine 2011;18(1):18-20.

[6] Vijeth SR, Dutta TK, Shahapurkar J. Correlation of renal status with hematological profile in viperine bite. American Journal of Tropical Medicine and Hygiene 1997;56(2):168-70.

[7] Ash T, Pandhiary KN, Mahapatra MK, et al. Acute renal failure in snake bite. J Assoc Physician India 2000;48:31.

[8] Thomas L, Tyburn B, Kelter'e J, et al. Prognostic significance of clinical grading of patients envenomed by Bothrops lanceolatus in Martinigua. Transactions of the Royal Society of Tropical Medicine and Hygiene 1998;92:542-5. 